\title{
Determination of Hole Location on Printed Circuit Boards
}

\section{RECEIVED BY TIC APR 191973}

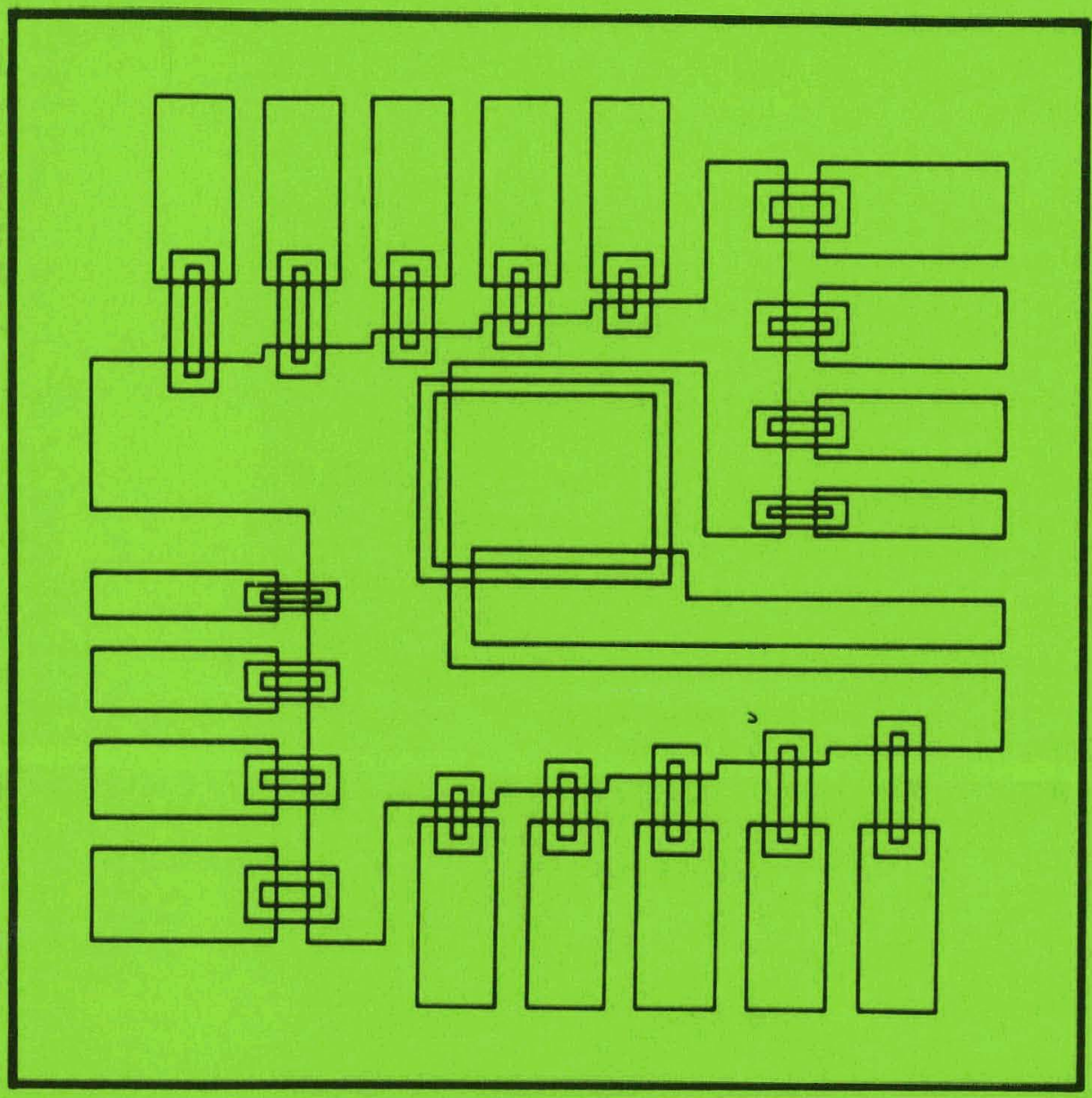

$B D X-6 \mid 3-814$

December, 1972

Project Leader:

R. D. Taylor

Department 445

Prepared for the U. S. Atomic Energy Commission Albuquerque Operations office under Contract Number AT $(29-1)-613$ USAEC. 


\section{DISCLAIMER}

This report was prepared as an account of work sponsored by an agency of the United States Government. Neither the United States Government nor any agency Thereof, nor any of their employees, makes any warranty, express or implied, or assumes any legal liability or responsibility for the accuracy, completeness, or usefulness of any information, apparatus, product, or process disclosed, or represents that its use would not infringe privately owned rights. Reference herein to any specific commercial product, process, or service by trade name, trademark, manufacturer, or otherwise does not necessarily constitute or imply its endorsement, recommendation, or favoring by the United States Government or any agency thereof. The views and opinions of authors expressed herein do not necessarily state or reflect those of the United States Government or any agency thereof. 


\section{DISCLAIMER}

Portions of this document may be illegible in electronic image products. Images are produced from the best available original document. 


\section{DETERMINATION OF HOLE LOCATION ON PRINTED CIRCUIT BOARDS}

$\mathrm{BDX}-613-814$

Distributed December 1972

Project Leader:

R. D. Taylor

Department 445

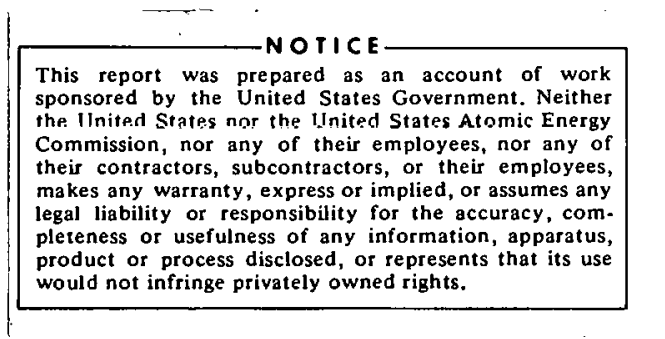

Tectnical Communications

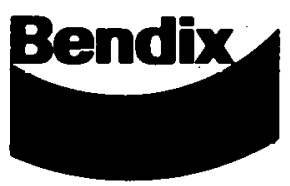

Kansas City Division

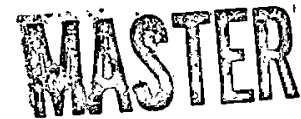


THIS PAGE

\section{WAS INTENTIONALLY LEFT BLANK}


DETERMINATION OF HOLE LOCATION ON PRINTED CIRCUIT BOARDS

BDX-613-814, UNCLASSIFIED, Distributed December 1972

Prepared by R. D. Taylor, D/445

An algorithm which determines the position of holes on printed circuit boards is described. Expected hole locations are input to the computer and true hole location and hole radius are determined from the digital image data. The true hole location and hole radius are presently printed out for human evaluation. Eventually hole ldcation will be compared with land location to ensure that the hole is concentric to the land within a given tolerance.

This report was prepared as an account of work.sponsored by the United States Government. Neither the United States nor the United States Atomic Energy Commission, nor any of their employees, nor any of their contractors, subcontractors, or their employees, makes any warranty, express or implied, or assumes any legal liability or responsibility for the accuracy, completeness or usefulness of any information. apparatus, product or process discilosed, or represents that its use would not infringe privately owned rights.
THE BENDIX CORPORATION

KANSAS CITY DIVISION

KANSAS CITY, MISSOURI

A prime contractor for the Atomic Energy Commission

Contract Number AT(29-1)-613 USAEC 
THIS PAGE

\section{WAS INTENTIONALLY LEFT BLANK}




\section{CONTENTS}

Section

Page

FOREWARD . . . . . . . . . . . . . . . . . . . .

SUMMARY . . . . . . . . . . . . . . . . . . . . .

DISCUSSION

SCOPE AND PURPOSE . . . . . . . . . . . . . . . . .

PRIOR WORK • . . . . . . . . . . . . . . . . .

ACTIVITY • • . . . . . . . . . . . . . . . . . .

Equipment and Test Material . . . . . . . . . . . .

The Algorithm . . . . . . . . . . . . . . . . .

ACCOMPLISHMENTS

FUTURE WORK • • . . . . . . . . . . . . . . .

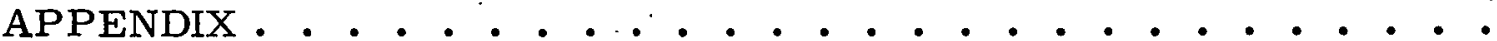


THIS PAGE

\section{WAS INTENTIONALLY \\ LEFT BLANK}




\section{ILLUSTRATIONS}

Figure

Page

1

Unwired Printed Circuit Board With Arrow Indicating the Three Holes to be Inspected (Polaroid)

Photographic Copy of Film Transparency Used for Scanning (Polaroid). . . . . . . . . • . . • .

Flowchart for Inspecting Hole Locations. . . . . . . .

Input Digital Image Array Reconstructed on DICOMED/Display (Polaroid). . . . . . . . . .

Subimage Specified by (I, J), The Expected

Hole Location. . . . . . . . . • . . . . . .

Distances $\mathrm{X} 1, \mathrm{X} 2$, and $\mathrm{Y} 1$ Measured in Subimage

$(\mathrm{I}, \mathrm{J})$, to Determine True Center . . . . . . . . .

Measurement of X1 and X2. . . . . . . . . . . .

Measurement of $\mathrm{Y} 1$. . . . . . . . . . . .

Output Image With Expected Hole Locations, True Hole Locations, and Computer-Constructed Circles (Polaroid) 


\section{THIS PAGE}

\section{WAS INTENTIONALLY LEFT BLANK}


Since 1971, The University of Missouri-Columbia, under contract to Bendix Kansas City Division, has studied automated inspection methods of printed circuit boards. This report, prepared by Dale A. Ausherman, is the fifth in a series of progress reports submitted to the Bendix Kansas City Division by the Image Analysis Laboratory, Department of Electrical Engineering, University of Missouri-Columbia. 
THIS PAGE

\section{WAS INTENTIONALLY LEFT BLANK}


Automated quality inspection of printed circuit boards was achieved by developing algorithms for computer-controlled inspection. The prototype computer-automated printed circuit board inspection system proved successful in inspecting both the printed circuits and the wiring assembly of a board. True hole location and hole radius are determined from digital image data. Future effort will involve a comparison of hole location with land location. 


\section{THIS PAGE}

\section{WAS INTENTIONALLY \\ LEFT BLANK}




\section{DISCUSSION}

\section{SCOPE AND PURPOSE}

This study is part of an overall investigation of a prototype computer-automated printed circuit board inspection system (APCIS). Such an automated error detection system will be implemented on a digital computer which will provide such services on a printed circuit board (PCB) assembly line as an automated scanning system and an automated error detection package capable of detecting missing or misplaced components and lands, discontinued or misplaced solder connections, and any external damages to the board itself. Incorporated within this package is an interconnection path width measurement technique which uses the principle of chain coding.

A specific inspection task is to determine the placement of printed circuit holes and to test these locations for a given accuracy, in addition to hole radius. Also, an inspector must determine how well-centered the hole is in its associated pad or land. This report presents a set of workable computer algorithms which accurately determine the location of circuit holes and their radius. These computer routines, with slight modifications, are ready for inclusion in the inspection library of APCIS, as mentioned in the preliminary system specification.

\section{PRIOR WORK}

The problems, and partial solutions, associated with circuit board inspection have been stated in four previous Missouri University reports. This project for improvement of visual inspection began in 1968, and in 1971 a one-year subcontract was made with Missouri University to develop a computer-automated PCB inspection system.

\section{ACTIVITY}

Equipment and Test Material

The PCB shown in Figure 1 has gold-plated circuit paths and is nearly 4.5 inches $(11.43 \mathrm{~cm})$ in diameter. To simulate the high resolution for this application and to permit scanning with the present laboratory scanner and optics equipment, a magnified photograph was made of the board section containing the three test holes and a film transparency was produced for 


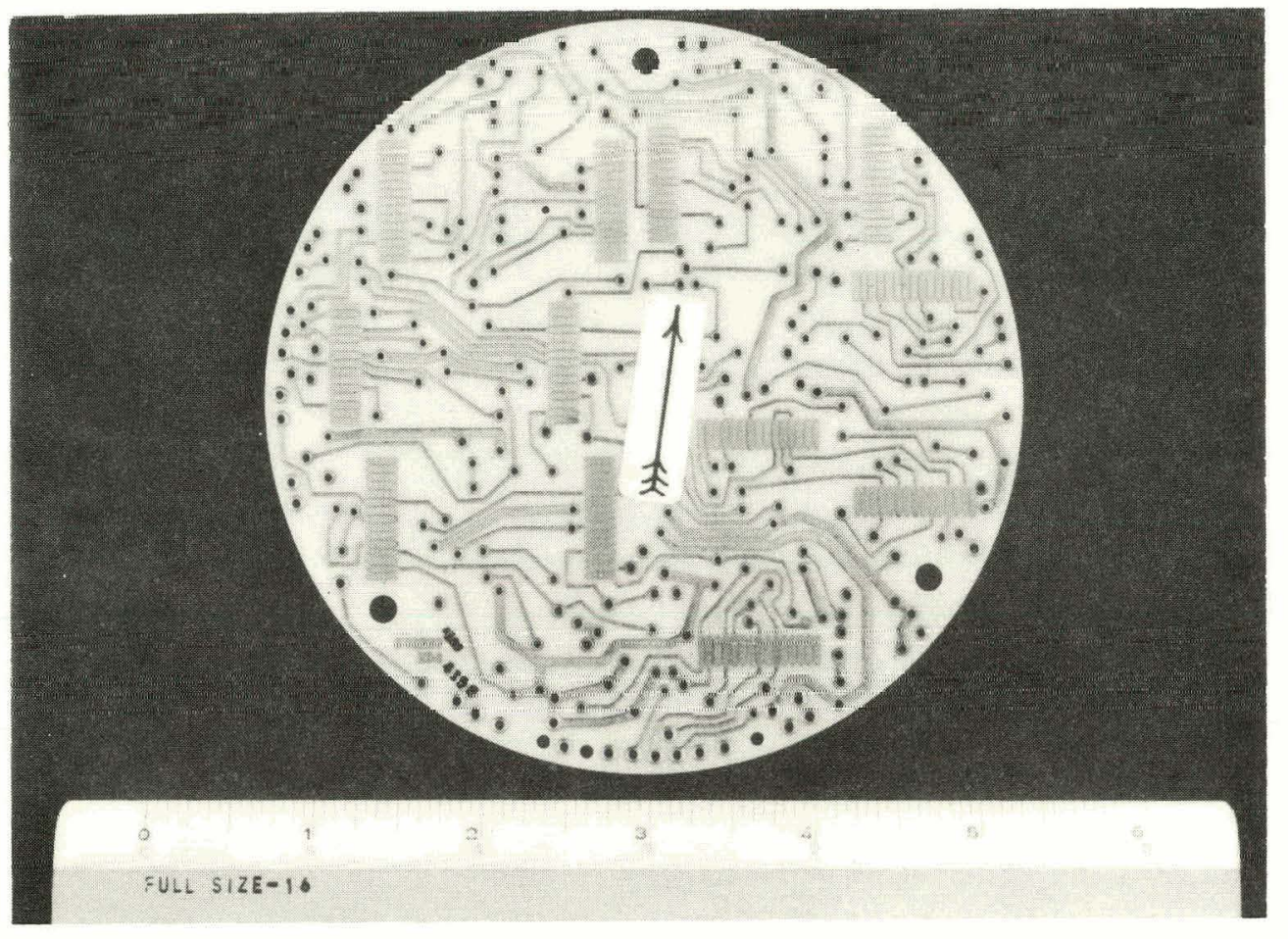

Figure 1. Unwired Printed Circuit Board With Arrow Indicating the Three Holes to be Inspected

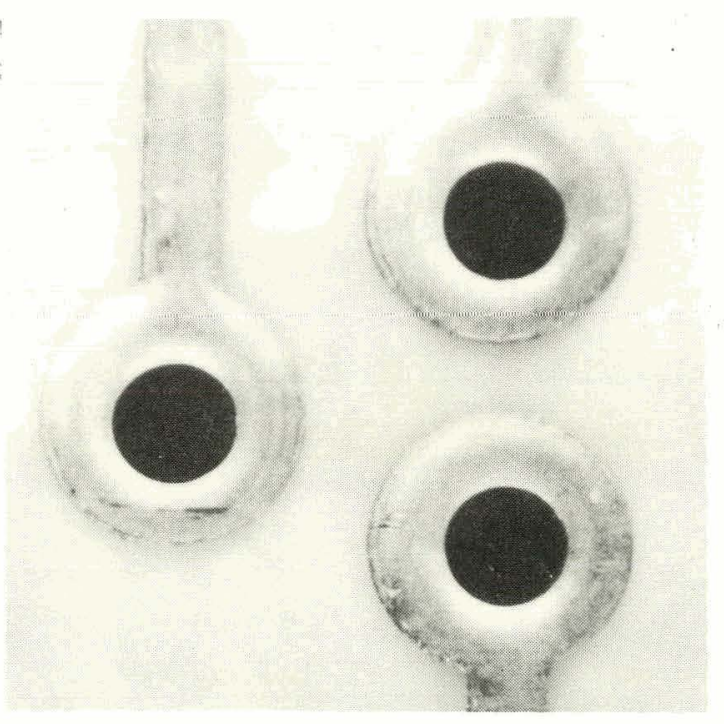

Figure 2. Photographic Copy of Film Transparency Used for Scanning 


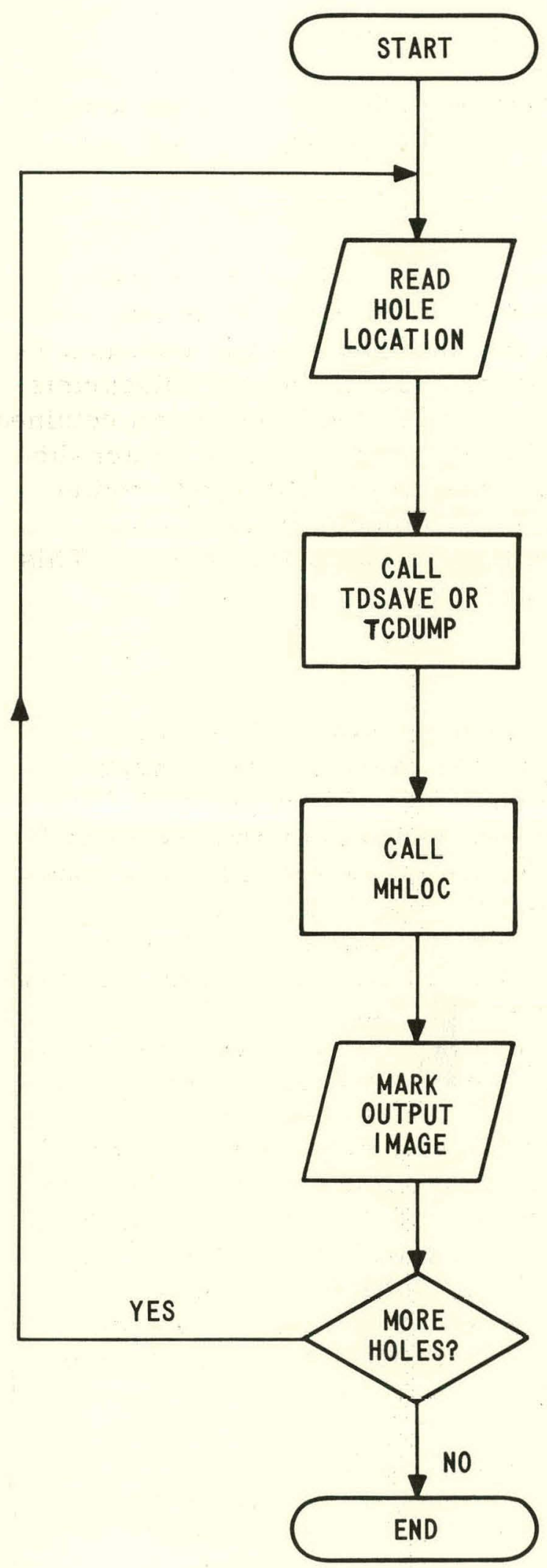

Figure 3. Flowchart for Inspecting Hole Locations 
scanning purposes (Figure 2). By scanning this transparency using a 256-by-256-image raster a sampling frequency of 750 samples per inch (295 samples per $\mathrm{cm}$ ) on the original board is simulated. If an edge can be determined to within \pm 1 sample, the measurement accuracy is $\pm 1.34 \mathrm{mils}$ $(0.0034 \mathrm{~cm})$. Nearly any desired accuracy can be obtained by using sufficient magnification prior to digitization.

The sequence the computer follows in this test is depicted by the flowchart in Figure 3. The expected location of each hole in the image to be inspected is input to the computer via punched cards containing the pairs of coordinates. In practice, these coordinates are easily obtainable from the PCB blueprints. The digital data in the vicinity of the expected coordinates is input and retained in core storage by routines TDSAVE or TCDUMP. The computer enters the image data currently in core storage. Using true hole location and radius, the computer then constructs a dotted circle on an output version of the digilal image to provide a visual check on the algorithm performance. This process is repeated for each hole to be inspected.

The Algorithm

Input to the computer consists of a 256 by 256-image array of integers ranging from 0 to 32,767 in increments of 32 (1024 discrete gray shade values) on magnetic tape, and one card for each hole to be inspected. The input image array is shown in Figure 4 after reconstruction of a real image on a DICOMED/30 image display. The entire 256-by-256-image array does not have to be in core at any one time because only a subset is needed to determine hole location and radius. This algorithm requires that only a 128 by 128 array be in core for measurement extraction. This array, called a subimage, is determined by the coordinates (I, J) of an expected hole location. The point $(I, J)$ is located at the center of the subimage (Figure 5). If elements of the subimage extend beyond the boundaries of the digital image, the elements are assigned a gray shade of zero. Data is dumped into core by routine TDSAVE or TCDUMP. When the first hole of a run is inspected, the image data resides on the input magnetic tape. The data is moved from the tape, through core, to a random access disc file. That data corresponding to the subimage defined by the first $(I, J)$ expected hole location is retained in core for measurement extraction. This initial data transfer is accomplished by TDSAVE. For the second and all succeeding holes the transfer consists simply of dumping the subimages from the disc file into core by using the TCDUJMP routine.

Once the subimage corresponding to a given hole location is in core, the routine MHLOC is entered by the computer. Figure 6 represents typical data in a subimage. The data is an array ( $I, J$ ) where $I$ and $J$ are integers 


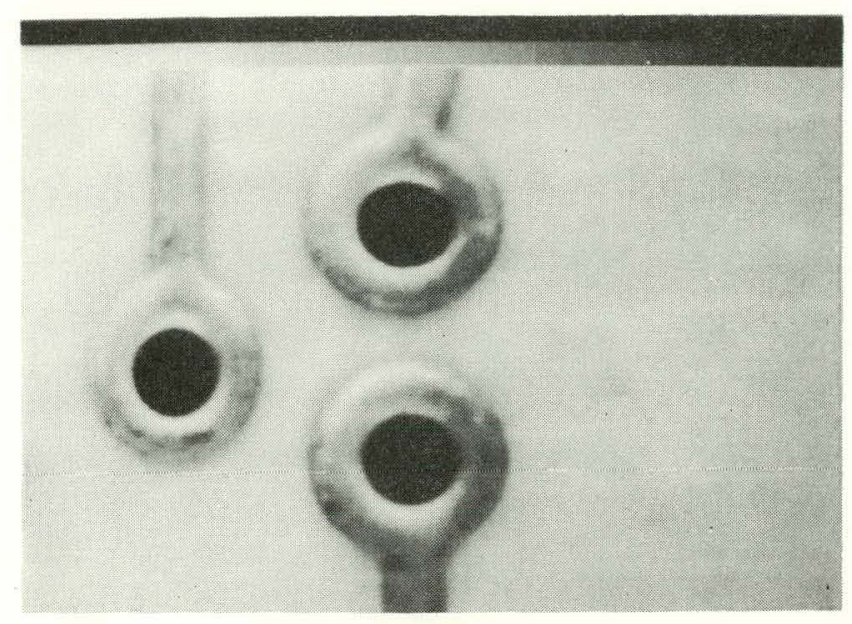

Figure 4. Input Digital Image Array

Reconstructed on

DICOMED/Display

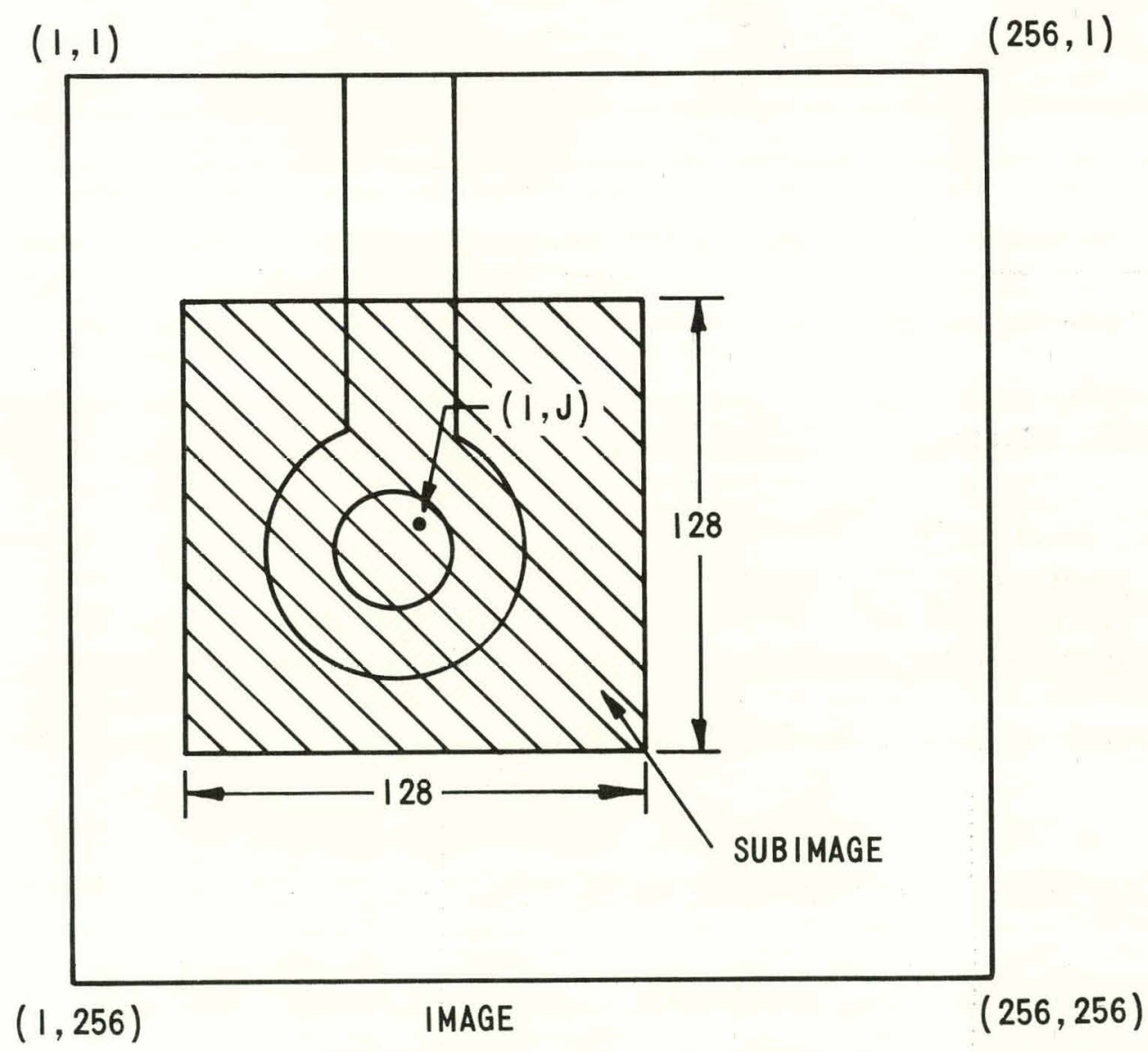

Figure 5. Subimage Specified by (I, J), The Expected Hole Location 


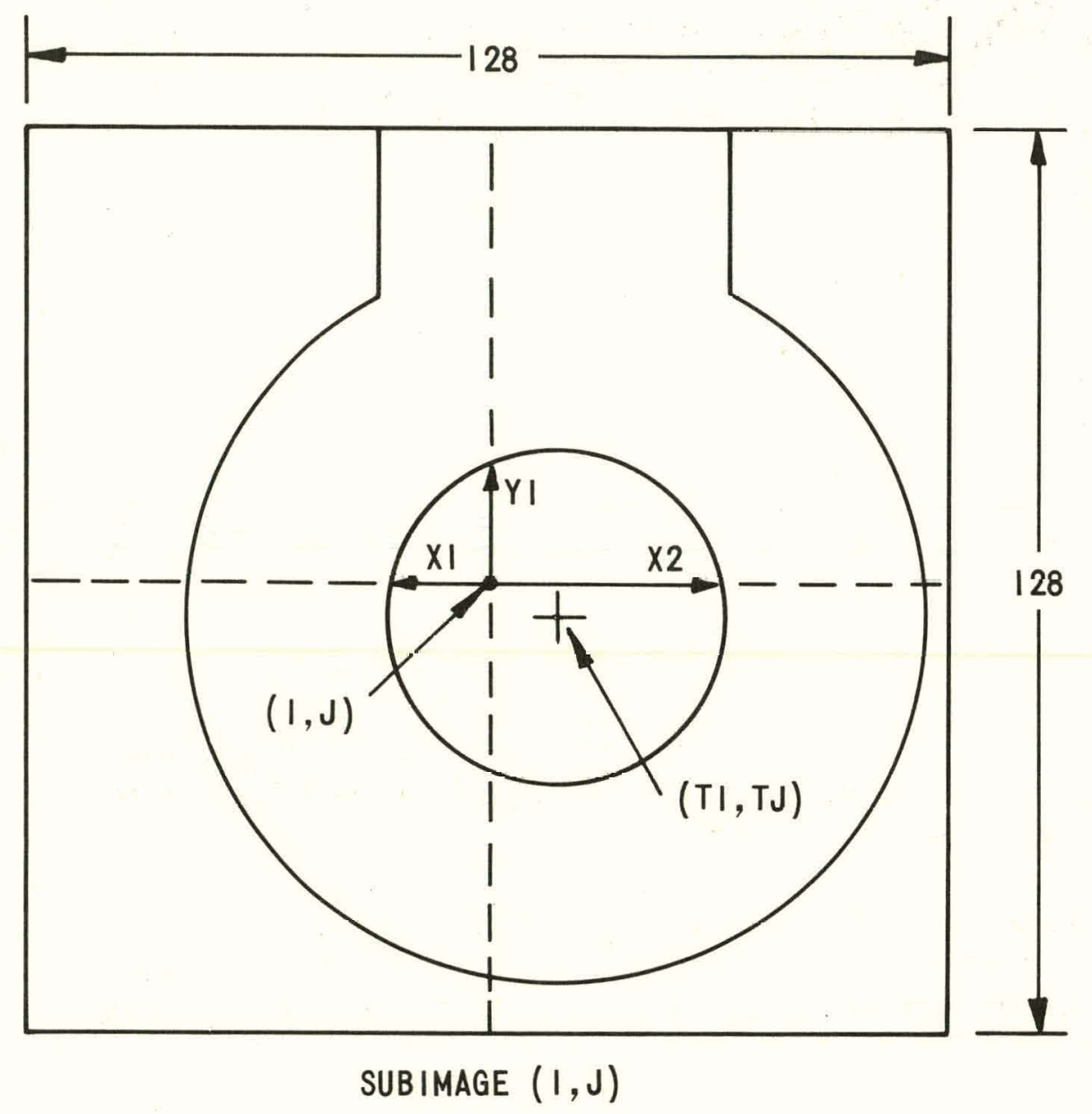

$(I, J)=$ EXPECTED HOLE CENTER

$(T I, T J)=$ TRUE HOLE CENTER (UNKNOWN)

$Y I=$ VERTICAL DISTANCE FROM $(I, J)$ TO EDGE

$X I=$ LEFT HORIZONTAL DISTANCE FROM $(I, J)$ TO EDGE

X2 = RIGHT HORIZONTAL DISTANCE FROM $(I, J)$ TO EDGE

Figure 6. Distances X1, X2, and Y1 Measured in Subimage $(I, J)$, to Determine True Center 
between 1 and 128. The expected center of the hole is located at $\mathrm{I}=64, \mathrm{~J}=64$, where the point $(1,1)$ is the upper left corner of the subimage. The true center of the hole ( $\mathrm{TI}, \mathrm{TJ}$ ) and the radius can be determined by measuring the distances X1, X2, and TI, as shown in Figure 6. The true center and radius are given by

$\mathrm{TI}=\mathrm{I}+\frac{\mathrm{X} 2-\mathrm{X} 1}{2}$

$\mathrm{T} J=\mathrm{J}-\frac{1}{2 \mathrm{Y} 1} \cdot\left[\mathrm{Y} 1^{2}-\mathrm{X} 1 \cdot \mathrm{X} 2\right]$, and

RADIUS $=\left[(T I-I)^{2}+(\mathrm{Y} 1+\mathrm{TJ}-\mathrm{J})^{2}\right]$

These equations result from finding the intersection of the perpendicular bisectors of the two chords determined by the pairs of points (X1,Y1) and (X2, Y1) using simple two-dimensional geometry.

The measurements $\mathrm{X} 1, \mathrm{X} 2$, and $\mathrm{Y} 1$ are obtained from the subimage by examining the 64th row and 64th column. A threshold is determined by finding the maximum and minimum grey shades contained in the subimage MAX and MIN, respectively.

THRESHOLD $=\frac{1}{8} \mathrm{MIN}+\frac{7}{8} \mathrm{MAX}$

Figure 7 shows how this threshold is used to determine the distances X1 and X2. The curve consists of the actual grey values from row 64 plotted on a calcomp plotter. The expected center, shown by the dashed line, is at $\mathrm{X}$ coordinate 64 . Similarly, Figure 8 shows the determination of $\mathrm{Y} 1$ using data from the 64th column of the subimage. All values, are found by beginning at the expected center and stepping outward, counting steps until the threshold is exceeded.

Once the true center coordinates and radius are found, the accuracy of the algorithm-extracted measurements must be determined. To this end, an output image is produced using routine MARK to provide a visual check of this process. For each inspected hole three items are marked on the output image. The expected hole location is marked by a small cross 


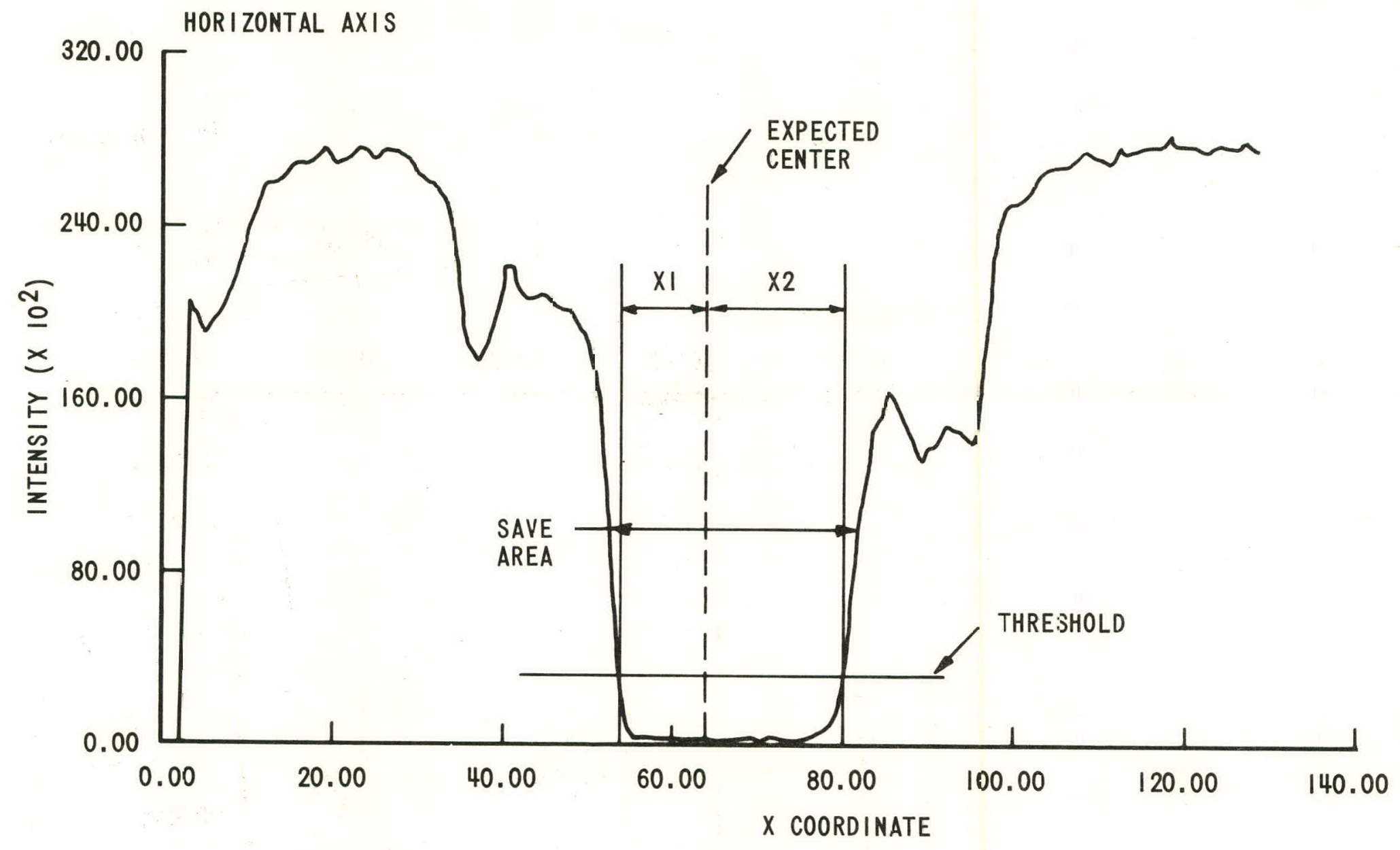

Figure 7. Measurement of X1 and X2 


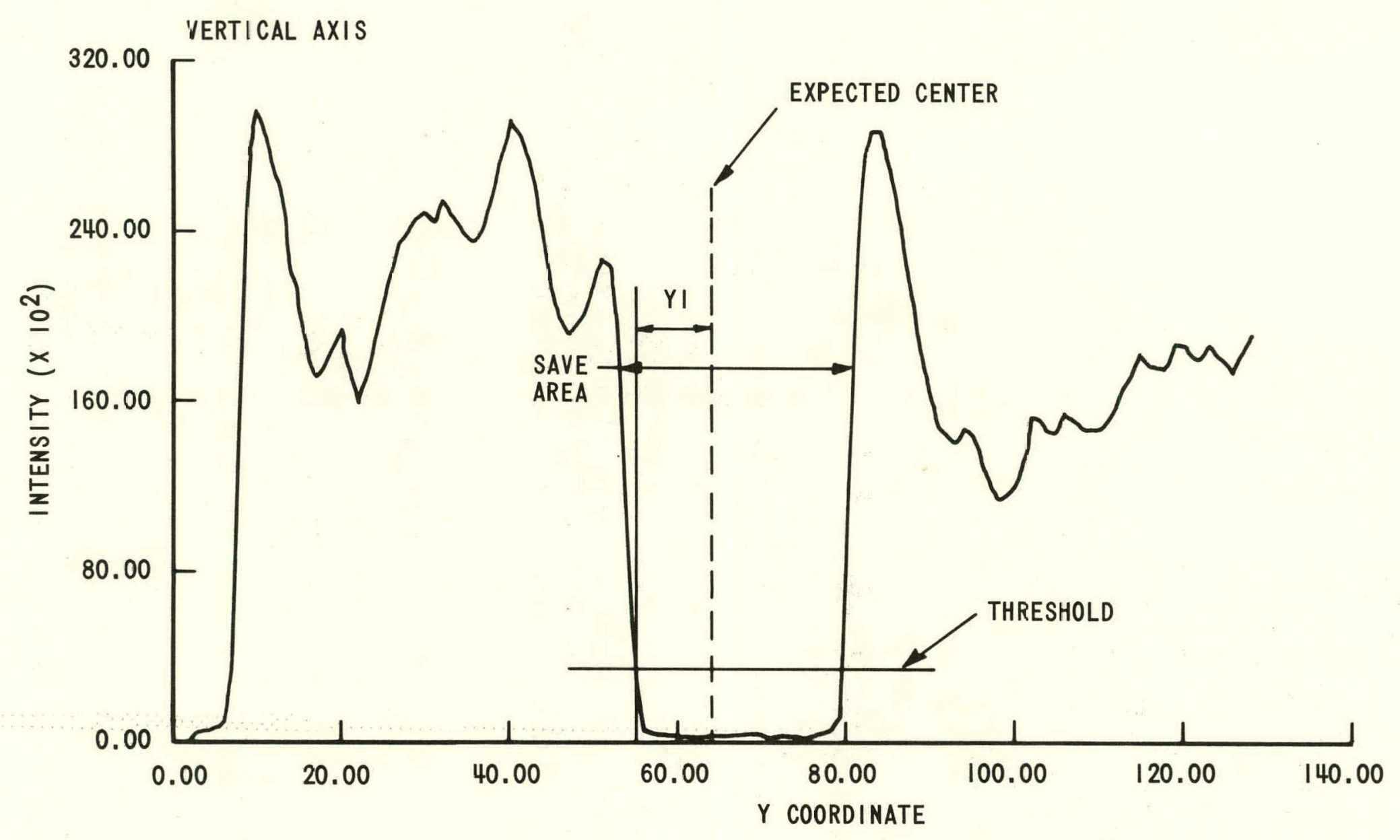

Figure 8. Measurement of $\mathrm{Y} 1$ 


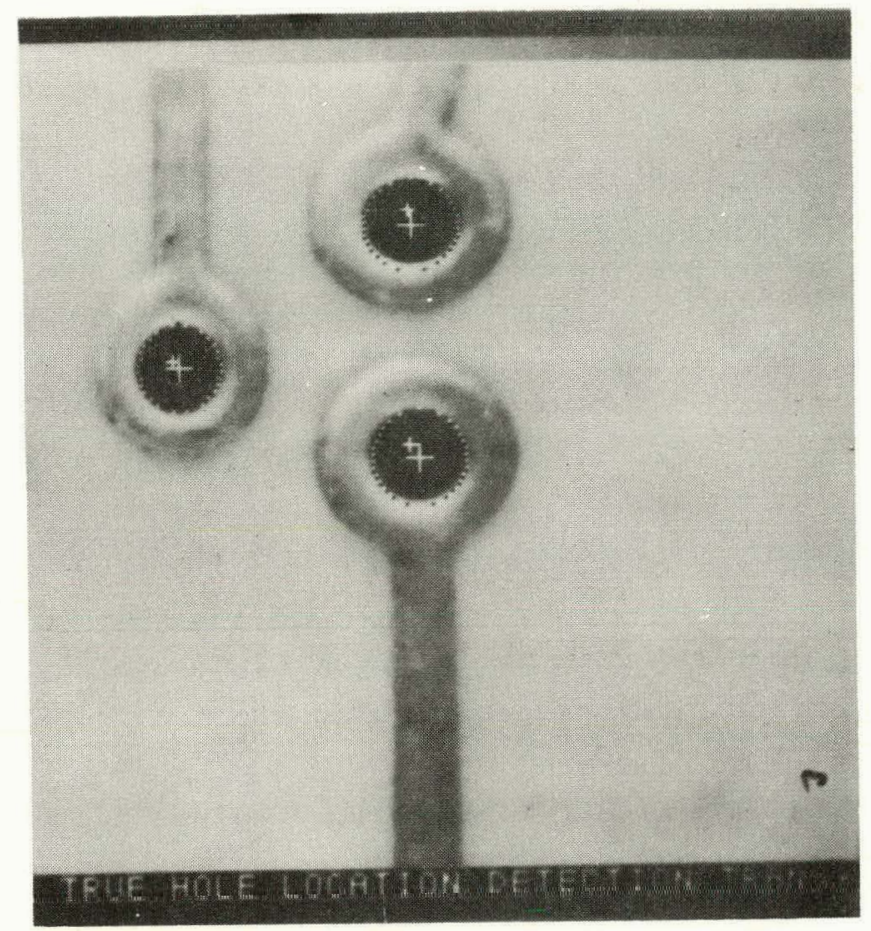

Figure 9. Output Image With Expected Hole Locations, True Hole Locations, and Computer-Constructed Circles

measuring five samples across. The true hole location is marked with a large cross measuring nine samples across. Finally, a circle is drawn that is centered at the true location and has a radius corresponding to the radius measured by MHLOC. In addition, a message is printed on the line printer of the form:

HOLE NO. 3 TRUE CENTER IS $(121,52)$ RADIUS = 14. 57.

An example of an output image with three holes inspected appears in Figure 9.

\section{ACCOMPLISHMENTS}

The algorithm developed in this project successfully determines circuit board hole location and radius, given expected hole location information. This is a significant step toward a totally automatic printed circuit inspec- 
tion system. One disadvantage of the present algorithm is that it assumes a hole does exist and that the expected hole location will fall somewhere inside the actual hole. These limitations can be overcome by searching, with gray shade information, certain predefined neighborhoods of the expected hole location for the existence of a hole. The current procedure is fast (1.15 minutes to inspect three holes with a high degree of accuracy). In practice, the computer will use the actual circuit board as a read-onlymemory, thus eliminating the intermediate storage devices, such as tape and disc.

\section{FUTURE WORK}

Additional routines should be added to the present package. Determination of pad location, pad size, and checking tolerances should be given first priority. Also, some of the techniques developed for measuring path width should be made compatible with this process. 


\section{THIS PAGE}

\section{WAS INTENTIONALLY LEFT BLANK}


REFERENCES

${ }^{1}$ Automatic Comparison System. 'Image Analysis Laboratory, University of Missouri--Columbia, December, 1971.

2 Investigation of Feasibility of Automatic Comparison System. Image

Analysis Laboratory, University of Missouri--Columbia, January, 1972.

${ }^{3}$ Registration of Printed Circuit Boards. Image Analysis Laboratory,

University of Missouri--Columbia, February, 1972.

${ }^{4}$ Preliminary System Specification: Automated Printed Circuit Inspection

System. Image Analysis Laboratory, University of Missouri--Columbia, February, 1972 .

25 
THIS PAGE

\section{WAS INTENTIONALLY LEFT BLANK}




\section{Appendix}

SUBROUTINES TDSAVE, TCDUMP, MHLOC, AND MARK 
THIS PAGE

\section{WAS INTENTIONALLY \\ LEFT BLANK}


FORTRAN IV G LEVEL 18

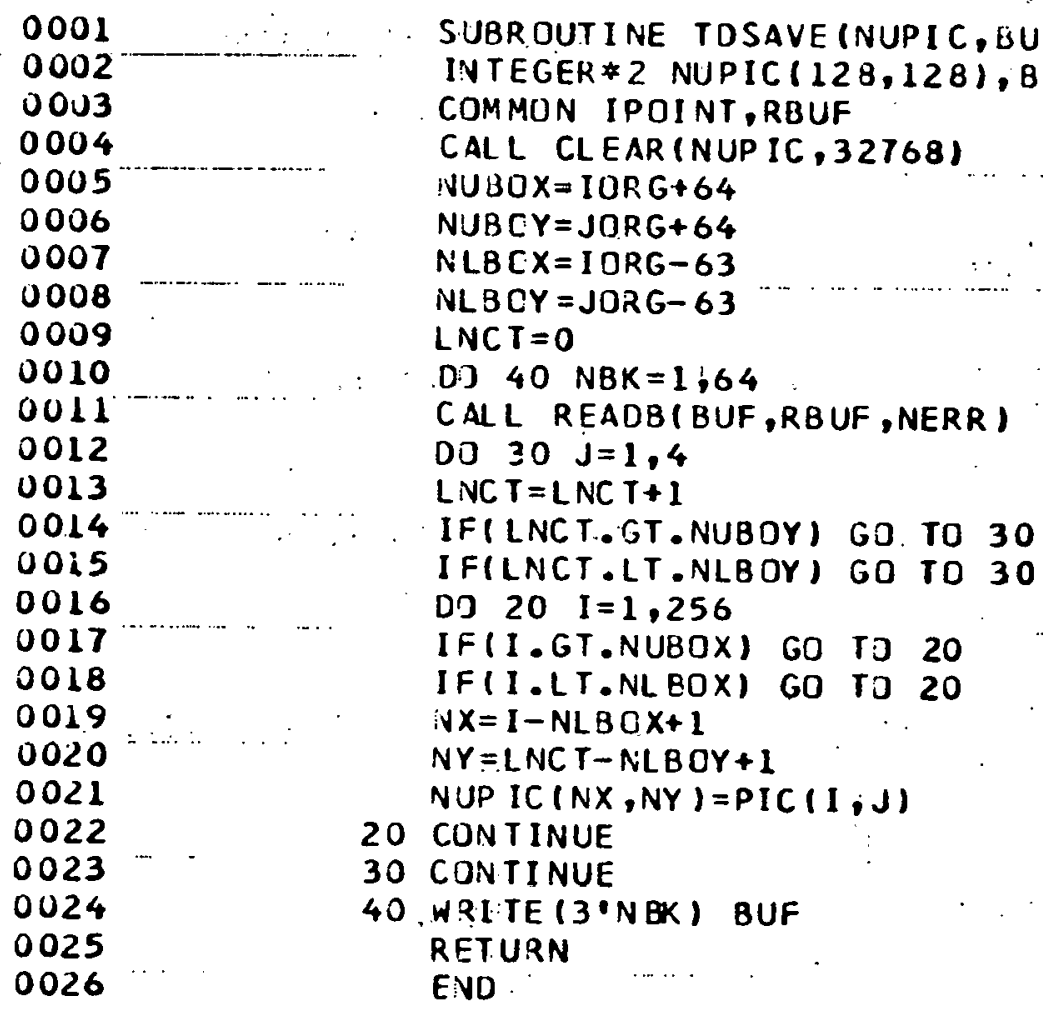




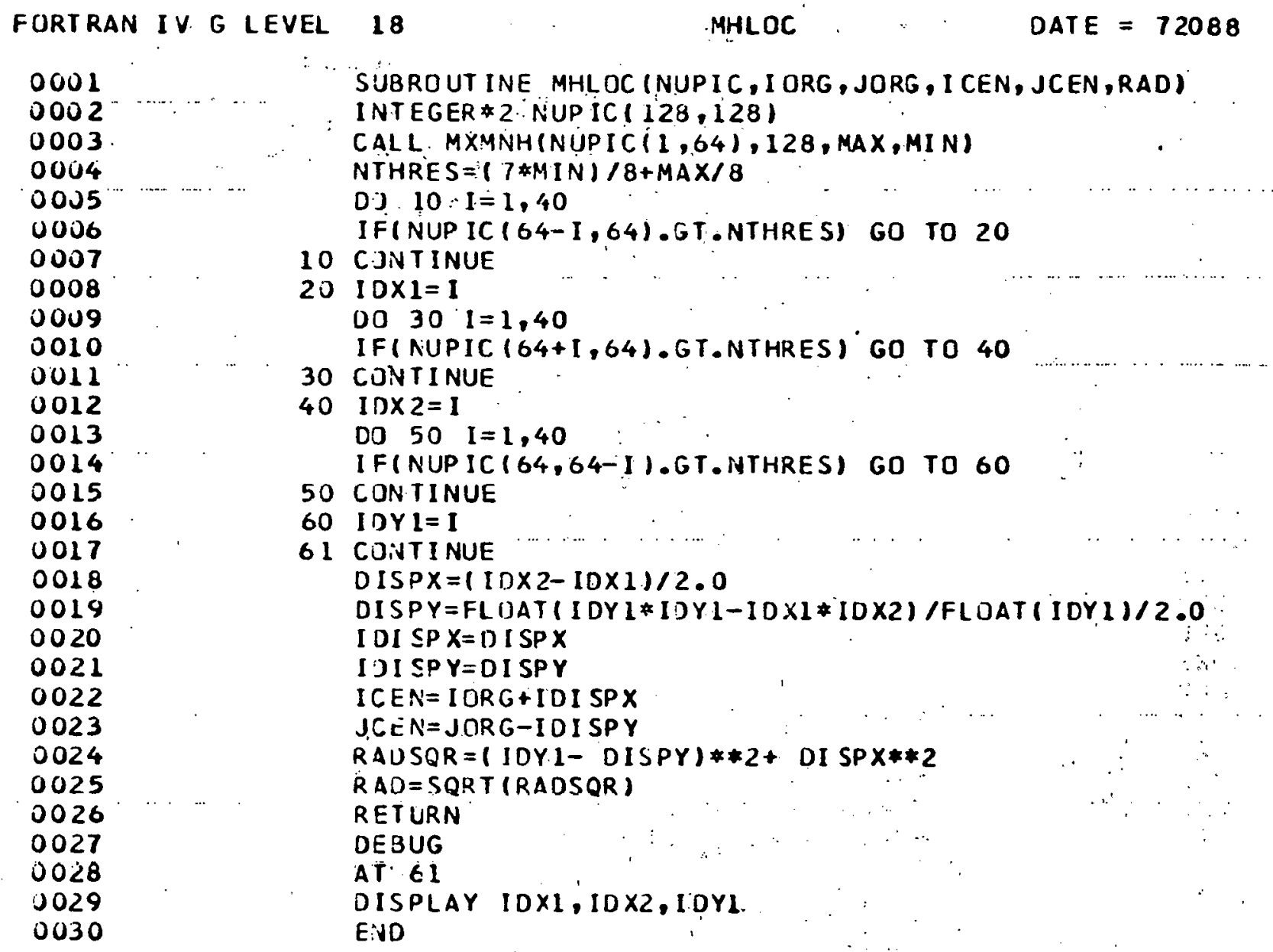


FORTRAN IV G LEVEL I

TCOUMP

DATE $=72088$

0001

0002

0003

0004

0005

0006

0007

0008

0009

0010

0011

0012

0013

0014

0015

0016

0017

0018

0019

0020

0021

0022

2023

0024

0025

0026

0027

0028

0029

0030

0031

0032

0033
SUBROUT I NE. TCDUMP. (NUP I C,BUF.,PIC, IORG, JORG)

INTEGER 2 NUPIC $(123,128), B U F(1024), P I C(256,4)$

COMMON IPOINT, RBUF

CALL CLEARINUPIC,32768)

10 CONTINUE

NUBOX $X=10 R G+64$

VUBCY $=J O R G+64$

NLBCX $=$ I ORG -63

NLBOY $=$ JORG -63

NDOFSET $=$ NLBOX

INBK $=(N L B O Y-1) / 4+1$

LNBK $=(N \cup B O Y-1) / 4+1$

IF (INBK.LT 1 I) I NBK $=1$

IF (LNBK. . T. . 64) LNBK $=64$

IF(NLBOX.LT . I) NLBOX $=1$

I F(NUBOX.GT.256) NUBOX $=256$

DO 40 NBK = INBK, LNBK

READ (3'NBK) BUF

$I N C=(N B K-1) * 4$

DO $30 \mathrm{~J}=1,4$.

LNC T $=$ INC $+\mathrm{J}$

IFILNCT.GT.NUBOY) GO TO-30.:

IF(LNCT.LT.NLBOY) GO TO 30

DO. 20 I $=$ NLBOX, NUBOX

$N X=I-N O F S E T+1$

$N Y=L N C T-N L B O Y+1$

NUP IC $(N X, N Y)=P I C(I, J)$

20 CONTINUE

30 CONTINUE

40 CONTINUE

11 CONTINUE

RETURN

END 


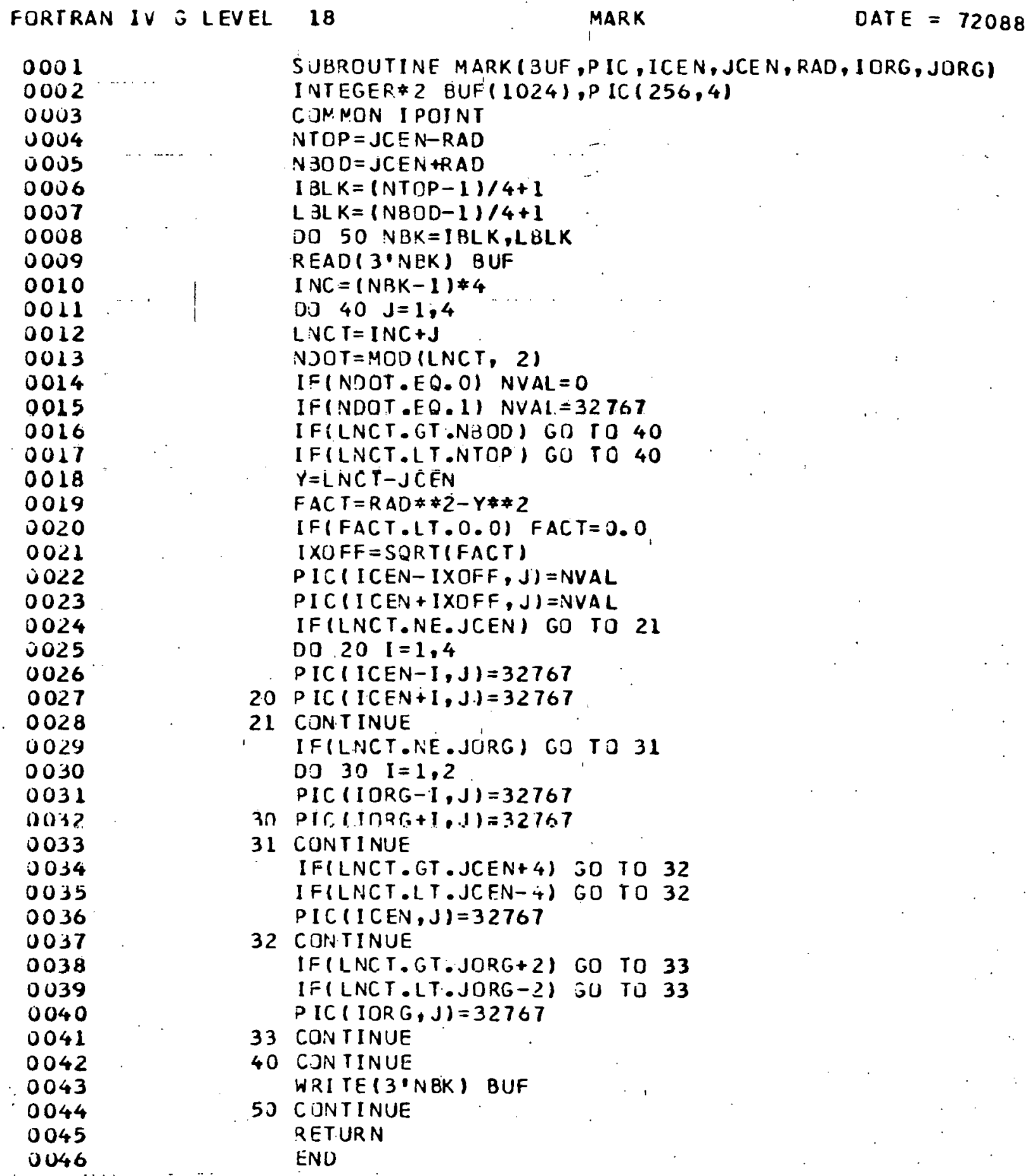

0001

0002

0003

0004

ט005

0006

0007

0008

0009

0010

0011

0012

0013

0014

0015

0016

0017

0018

0019

0020

0021

0022

0023

0024

0025

0026

0027

0028

0029

0030

0031

003 ?

0033

0034

0035

0036

0037

0038

0039

0040

0041

0042

0043

0044

0045

0046

SUBROUTINE MARK ( 3 UF, P IC, ICEN, JCEN, RAD, I ORG, JORG)

INTEGER $* 2$ BUF $(1024), P$ IC $(256,4)$

C.JMMON I POINI

NTOP $=J C E N-R A D$

$N 30 D=J C E N+R A D$

I $B L K=(N T O P-1) / 4+1$

$L Z L K=(N B O D-1) / 4+1$

DO $50 N B K=I B L K, L B L K$

READ ( 3 'NEK) BUF

$I N C=(N B K-1) \neq 4$

D. $40 \quad J=1,4$

$L N C T=I N C+J$

NJOT $=$ MOD (LNCT, 2)

IF(NDOT.EQ.0) NVAL $=0$

IFINDOT .EQ.1) NVAL $=32767$

IF(LNCT.GT.NBOD) GD TO 40

IFILNCT.LT.NTOP) GO TO 40

$Y=L N C T-J \bar{C} \overline{E N}$

$F A C T=R A D * \# Z-Y * \# 2$

IFIFACT .LT.0.0) FACT $=0.0$

IXOFF $=S Q R T(F A C T)$

$P$ IC ( ICEN-IXOFF, J) =NVAL

PIC (ICEN + IXDFF, J) =NVAL

IF(LNCT.NE.JCEN) GO TO 21

DO $20 \quad I=1,4$

$P[C($ ICEN-I, J $)=32767$

$20 P$ IC (ICEN+I, J $)=32767$

21 CONTINUE

IF(LNCT.NE.JURG) CO TO 31

D) $30 \quad I=1,2$

$P I C(I O R G-I, J)=32767$

3ก $P(r, \operatorname{lin} R,+1, .1)=32767$

31 CONTINUE

IF(LNCT.GT.JCEN+4) 30 TO 32

I F(LNCT.LT.JCEN-4) GO TO 32

$P[C(I C E N, J)=32767$

32 CONTINUE

IF (LNCT.GT.JORG+2) GO TO 33

IF(LNCT.LT.JORG-2) SU TO 33

$P I C(I O R G, J)=32767$

33 CON TINUE

40 CON TINUE

WRITE(3'NBK) BUF

50 CONTINUE

RETURN

ENO 